\title{
Norbert Schwarz: A Pioneer in Social Indicators and Quality of Life Research
}

\author{
Norbert Schwarz ${ }^{1}$
}

Received: 5 April 2015 /Accepted: 1 August 2015/Published online: 23 August 2015

(C) Springer Science+Business Media Dordrecht and The International Society for Quality-of-Life Studies (ISQOLS) 2015

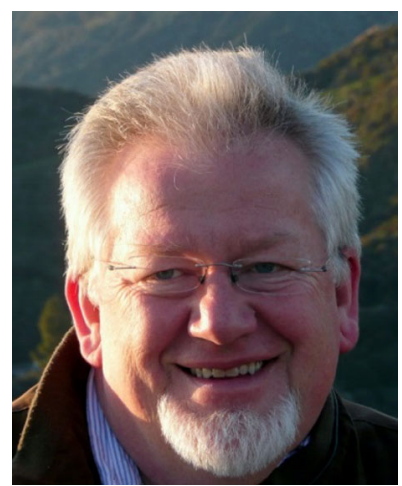

Most well-being research asks what makes for a happy and satisfying life, focusing on societal conditions and individual activities. In contrast, my research mostly asked how people evaluate their lives: When asked how happy or satisfied they are, how do people arrive at an answer? In the 1970's I studied sociology at the University of Mannheim, Germany, where Wolfgang Zapf (see "pioneers" entry on Zapf; Glatzer, 2012) developed a German social indicators system building on research at Michigan's Institute for Social Research (see "pioneers" entries on Campbell and Andrews; Michalos, 2014a, b). This work treated well-being reports as veridical read-outs of relatively stable inner states. At the same time, research in cognitive and social psychology began to emphasize the context sensitive nature of human judgment. Social psychologists at the University of Mannheim were introduced to this development through visits of Robert S. Wyer, of the University of Illinois, a pioneer of information

Norbert Schwarz

norbert.schwarz@usc.edu

1 Mind \& Society Center, University of Southern California, Los Angeles, CA 90089-3331, USA 
processing approaches. The contrast was striking. On the one hand, psychologists found that judgments of important issues were easily swayed by minor contextual influences; on the other hand, social scientists used such judgments at face value in monitoring social change and explaining social behavior. Clearly, understanding how survey respondents arrive at the answers that social scientists use as data had the potential to contribute to both fields.

Two other graduate students -Fritz Strack, a psychologist, and Hans-Jürgen Hippler, a sociologist - were similarly intrigued and these issues became major themes of our work. Initially greeted with considerable doubt, the investigation of the cognitive and communicative underpinnings of survey responses developed into an active interdisciplinary field (for a review, see Schwarz 1999).

\section{A judgment model of evaluative well-being}

If taken literally, asking people to evaluate their lives as a whole, taking all things together, poses an impossible task. Not surprisingly, they don't proceed that way (for a review, see Schwarz and Strack 1999). As in other domains of judgment, they rely on what comes to mind at the moment, which reflects enduring concerns as well as temporary influences. Moreover, the same information can influence well-being judgments in opposite directions, depending on how it is used. A past negative life-event, for example, decreases life-satisfaction when it is thought of as a feature of one's life, but increases life-satisfaction when it is used as a standard against which one's current life is evaluated. The underlying mental construal processes are well understood and hold across content domains.

As an alternate route, people can simplify the assessment by asking themselves, "How do I feel about my life?" This results in more positive evaluations of one's life under happy rather than sad moods. The influence of mood is eliminated when people are aware that their current feelings are due to an irrelevant influence, from weather conditions to finding a dime or the outcome of a sports event. Again, the same processes hold in other domains as conceptualized in feelings-as-information theory (for a review, see Schwarz 2012).

\section{Experienced well-being}

Given the context sensitive nature of evaluative judgment, the observed relationship between objective conditions of life and their subjective evaluation is necessarily weak. An alternative approach to well-being asks how people experience their lives moment to moment, which can be addressed with experience sampling methods. Because the burden of these methods precludes their use in representative samples I joined an interdisciplinary team, led by Daniel Kahneman, to develop an approximation that is suitable for larger samples. Our Day Reconstruction Method (DRM; Kahneman et al. 2004) assesses what people do with whom for how long and how they feel while doing it. The findings consistently highlight the importance of activities in experienced wellbeing. For example, wealth is even less influential in people's moment-to-moment affective experience than in their evaluation of life-as-a-whole. 


\section{A personal journey}

The tension between the context sensitive and constructive nature of human judgments and their use in social science research brought me from graduate school in sociology to a post-doctoral year in psychology at the University of Illinois at Urbana-Champaign (1980/81), with Bob Wyer and Gerald Clore. Returning to Germany, I joined the psychology department at the University of Heidelberg (1981-1992) but stayed involved in social science research, serving as Scientific Director of ZUMA (now GESIS, 1987-1992), a social science research center. Following an invitation from the Institute for Social Research at the University of Michigan, I returned to the United States in 1993 and spent two stimulating decades at Michigan, where I also held appointments in the Department of Psychology and Ross School of Business. More recently, I joined the University of Southern California (2014) as co-founder of the USC Dornsife Mind \& Society Center, which aims to bring current understandings of the mind to bear on societal issues. Along the way, I have been fortunate to see my work recognized through election to the American Academy of Arts and Sciences (2004) and the German National Academy of Science (2009) as well as scientific contribution awards on both sides of the Atlantic, including the Wilhelm Wundt Medal of the German Psychological Society (2004, with Fritz Strack), the Wilhelm Wundt - William James Award of the American Psychological Association and European Federation of Psychologists' Associations (2009), and the Campbell Award of the Society for Personality and Social Psychology (2014).

\section{Selected References}

Kahneman, D., Krueger, A. B., Schkade, D., Schwarz, N., \& Stone, A. A. (2004). A survey method for characterizing daily life experience: the day reconstruction method (DRM). Science, 306, 1776-1780.

Glatzer, W. (2012). Wolfgang Zapf - a pioneer in social indicators- and quality of life- research. Applied Quality of Life Research, 7, 453-457

Michalos, A. C. (2014a). Angus Campbell: A pioneer in social indicators and social reporting. Applied Research Quality Life, 9, 781-782.

Michalos, A. C. (2014b). Frank M. Andrews: A pioneer in social indicators and social reporting. Applied Research Quality Life, 9, 779-780.

Schwarz, N. (1999). Self-reports: how the questions shape the answers. American Psychologist, 54, 93-105. Schwarz, N. (2012). Feelings-as-information theory. In P. A. M. Van Lange, A. Kruglanski, \& E. T. Higgins (Eds.), Handbook of theories of social psychology (pp. 289-308). Thousand Oaks: Sage.

Schwarz, N., \& Strack, F. (1999). Reports of subjective well-being: Judgmental processes and their methodological implications. In D. Kahneman, E. Diener, \& N. Schwarz (Eds.), Well-being: The foundations of hedonic psychology (pp. 61-84). New York: Russell-Sage. 